\begin{tabular}{|c|c|}
\hline Title & $\begin{array}{l}\text { Parameter tuning in the support vector machine and random forest and their performances in cross and same year crop } \\
\text { classification using TerraSA R-X }\end{array}$ \\
\hline Author(s) & Sonobe, Rei; Tani, Hiroshi; Wang, X iufeng; Kobay ashi, Nobuyuki; Shimamura, Hideki \\
\hline Citation & $\begin{array}{l}\text { International Journal of Remote Sensing, 35(23), } 7898.7909 \\
\text { https://doi.org/10.1080/01431161.2014.978038 }\end{array}$ \\
\hline Issue Date & 201411 \\
\hline Doc URL & http:/hdl. handle.net/2115/60345 \\
\hline Rights & $\begin{array}{l}\text { This is an A ccepted Manuscript of an article published by Taylor \& Francis in International Journal of Remote Sensing } \\
\text { on 2014, avail able online: http://www.tandfonline.com/10.1080/01431161.2014.978038 }\end{array}$ \\
\hline Type & article (author version) \\
\hline File Information & manuscript_IJRS-2014.pdf \\
\hline
\end{tabular}

Instructions for use 
1 Parameter tuning in the support vector machine and random forest

2 and their performances in cross- and same-year crop classification

3 using TerraSAR-X

4 Rei Sonobe*a, Hiroshi Tani ${ }^{\mathrm{b}}$, Xiufeng Wang ${ }^{\mathrm{b}}$, Nobuyuki Kobayashic ${ }^{\mathrm{c}}$ and

5 Hideki Shimamura $^{\mathrm{d}}$

6 a JSPS Research Fellow / Graduate School of Agriculture. Hokkaido University,

7 Sapporo, Hokkaido 060-8589, Japan

$8{ }^{b}$ Research Faculty of Agriculture. Hokkaido University, Sapporo, Hokkaido 060-8589,

9 Japan

$10{ }^{c}$ Smart Link Hokkaido, Iwamizawa, Hokkaido 068-0034, Japan

$11{ }^{d}$ PASCO Corporation, Meguro-Ku, Tokyo 153-0043, Japan

12

13 Corresponding author

14 Kita 9, Nishi 9 Kita-ku, Sapporo, 060-8589, Japan

15 reysnb@gmail.com

16 


\section{Parameter tuning in the support vector machine and random forest \\ 2 and their performances in cross- and same-year crop classification using TerraSAR-X}

This paper describes the comparison of three different classification algorithms for mapping crops in Hokkaido, Japan, using TerraSAR-X data. In the study area, beans, beets, grasslands, maize, potatoes and winter wheat were cultivated. Although classification maps are required for management and for the estimation of agricultural disaster compensation, those techniques have yet to be established. Some supervised learning models may allow accurate classification. Therefore, comparisons among the classification and regression tree (CART), the support vector machine (SVM) and the random forests (RF) were performed. SVM was the best algorithm in this study, achieving overall accuracies of $89.1 \%$ for the same-year classification, which is the classification using the training data in 2009 to classify the test data in 2009 , and $78.0 \%$ for the cross-year classification, which is the classification using the training data in 2009 to classify the data in 2012.

\section{Introduction}

Land-cover classification is one of the most common applications of remote sensing.

Crop type classification maps are useful for estimating the amount of crops harvested or agricultural disaster compensation. Furthermore, the ability to generate crop type classification maps without concurrent training data is useful for reducing labour costs for the management of the agricultural field and early information gathering. Optical remote sensing is still one of the most attractive options for obtaining biomass information, and new sensors are available with fine spatial and spectral resolutions (Sarker and Nichol 2011). In addition, some optical satellites, such as Landsat, have been used for crop type classification (Hartfield et al. 2013; Mishra and Crews 2014). Significant information about soil and vegetation parameters has also been obtained through microwave remote sensing, and these techniques are increasingly being used to 
1 manage land and water resources for agricultural applications (Fontanelli et al. 2013).

2 Unlike passive systems, synthetic aperture radar (SAR) systems are not dependent on

3 atmospheric influences or weather conditions; thus, they are especially suitable for a

4 multi-temporal classification approaches (Bargiel and Herrmann 2011). The number of

5 studies on rice monitoring and mapping using SAR data has increased, and there are

6 strong correlations between the backscattering coefficients and the plant height and age.

7 There are examples of uses for crop growth monitoring of beets (Vyas et al. 2003),

8 maize (Beriaux et al. 2013; Blaes et al. 2006), and wheat (Fontanelli et al. 2013;

9 Lievens and Verhoest 2011; Mattia et al. 2003; Sonobe et al. 2014c). Furthermore, SAR

10 data have been used to identify specific crop types, such as paddy fields (Choudhury

11 and Chakraborty 2006; Kuenzer and Knauer 2013). The basic idea of these studies is to

12 use multi-temporal SAR data within a vegetation period to clarify the change pattern

13 with the time series (Costa, 2004), and it may be applied for other crop types. The

14 backscattering coefficient is a function of the geometry and dielectric properties of the

15 target and the amount of biomass in agricultural fields. Therefore, different types of

16 temporal changes can be distinguished with multi-temporal SAR data. The first large

17 backscatter intensity change occurs as a result of ploughing and seeding. Smaller

18 changes occur due to variations of biomass and plant water content, and, for X-band

19 SAR data, changes in the plant structure. Furthermore, harvesting causes large

20 backscatter intensity changes (Blaes and Defourny 2003; Sonobe et al. 2014a).

21 Sometimes, however, no backscatter intensity change is observed despite geometric

22 changes. This is typically observed for dense vegetation, such as grasslands, for high

23 frequency SAR data, such as C-band (Blaes and Defourny 2003). This indicates the

24 potential of the discrimination between gramineous crops (grass and wheat in this

25 study) and others. Sonobe et al. (2014b) shows the potential of X-band SAR data for 
mapping winter-wheat planted areas by Otsu's method (Otsu, 1979). combination of SAR frequencies, polarisations, and incidence angles that is most suitable for best retrieving soil and vegetation parameters (Ulaby et al. 1986). Multi-temporal dual polarimetric (HH/VV) TerraSAR-X data acquired in StripMap mode were obtained, and the resolutions were $2.75 \mathrm{~m}$ in the enhanced ellipsoid corrected format. TerraSAR-X was launched on June 15, 2007, and X-band previous studies have proven the high geometric accuracy of TerraSAR-X (Ager and Bresnahan 2009). The robustness of the multi-temporal classification approach with high-resolution TerraSAR-X spotlight data was also shown for a same year classification (Bargiel and Herrmann 2011). However, in order to reduce the labour the use of training data selected in another year should be considered.

6 Within this framework, the main objectives of the present study are to evaluate without concurrent training data.

\section{Study Area}

The experimental area of this study (Figure 1) is the farming area in western Tokachi plain, Hokkaido, Japan $\left(142^{\circ} 55^{\prime} 12^{\prime \prime}\right.$ to $143^{\circ} 05^{\prime} 51^{\prime \prime} \mathrm{E}, 42^{\circ} 52^{\prime} 48^{\prime \prime}$ to $\left.43^{\circ} 02^{\prime} 42^{\prime \prime} \mathrm{N}\right)$ at an summers and cold winters with an average annual temperature of $6^{\circ} \mathrm{C}$ and annual precipitation of $920 \mathrm{~mm}$.

SAR signals acquired under different polarisations show different backscatter responses, providing more information about vegetation (Brisco et al. 2013) There is a SAR data are widely available and often operated with dual polarisations. Furthermore, costs for the selection of training data, which are sometimes collected by in situ surveys, the potential of Terra-SAR-X data for crop type classification and crop map generation elevation between 50 and $230 \mathrm{~m}$. The climate of the study area is characterised by warm 
1 The dominant crops are beans (azuki and soy), beets, grasslands, maize (dent corn and

2 sweet corn), potatoes and winter wheat. A total of 4,955 fields (1,053 beans fields, 709

3 beet fields, 623 grasslands, 254 maize fields, 831 potato fields and 1,485 winter wheat

4 fields) covered the area in 2009, and 5,074 fields (960 bean fields, 625 beet fields, 644

5 grasslands, 583 maize fields, 749 potato fields and 1,513 winter wheat fields) covered

6 the area in 2012. The mean size of a fields is 2.16 ha (the maximum area is 18.0 ha and

7 the smallest area is $0.01 \mathrm{ha}$ ). The cultivation calendar for the crops in this study area is

8 shown in Table 1.

9

10

\section{3. Data and methods}

\subsection{Data}

$<$ Figure 1>

<Table 1>

X-band SAR (TerraSAR-X or TanDEM-X) data were acquired on 7 July, 9 August, 31 August and 11 September, 2009, and on 11 July, 2 August, 24 August and 15

September, 2012 (Table 2). The SAR used in this study area was side-looking SARs based on active phased-array antenna technology that flies in a sun-synchronous dawndusk orbit with an 11-day repeat at an altitude of $514 \mathrm{~km}$ at the equator (Roth et al. 2004). Multi-temporal sigma naught data have been revealed to be effective for crop type classification (Bargiel and Herrmann 2011). Therefore, in this study, L1B enhanced ellipsoid corrected products operated in StripMap mode were converted from digital numbers to gamma naught. Then, the mean gamma naught values were calculated for fields for each observation day using field polygons (shape file format) provided by Tokachi Nosai (http://www.tokachi-nosai.or.jp/). These processes were conducted using ERDAS IMAGINE version 14.0 distributed by Intergraph Corporation. 
1 Table 3 represents the numbers of fields of each crop type.

2

3

\section{$4 \quad 3.2$ Classification algorithm and evaluation}

5 We used multi-temporal backscatter coefficients for crop classification, and the whole

6 processing workflow is illustrated in Figure 2. These classification algorithms were

7 applied using R, which provides a wide variety of statistical (linear and nonlinear

8 known. The optimisation problem is solved by mapping the samples into a higher-

modelling, classical statistical tests, time-series analysis, classification, clustering) and graphical techniques, and is highly extensible (R Core Team 2013).

$<$ Figure 2>

In earlier studies, the classification and regression tree (CART) was used to identify crops among alfalfa, corn, cotton, grain, melon orchards and sorghum from Landsat Thematic Mapper (TM) image data, achieving overall accuracies of 87 to $92 \%$ for the data acquired in 2008. Furthermore, using training data from one year and applying that data to another year for classification purposes demonstrated that overall accuracies from $71 \%$ to $83 \%$ are achievable, although accuracies were consistently greater than 85\% for some crops (Hartfield et al. 2013). In addition to CART, two widely used supervised learning models, the support vector machine (Bovolo et al. 2010; Foody and Mathur 2004; Lizarazo 2008; Pal 2008) and random forest (Duro et al. 2012; Gislason et al. 2006; Kavzoglu and Colkesen 2013; Pal 2005; Rodriguez-Galiano et al. 2012), were performed in this study.

SVM builds a model that predicts target values when only the attributes are dimensional space using kernel functions. Instead of modelling probability densities, 
1 SVM uses the marginal sample and most discriminative samples (Cortes and Vapnik

2 1995). SVM provides sparse models where only a small number of samples are

3 assigned non-zero weights. These samples, called Support Vectors (SV), lie close to the

4 decision surface. The weights or coefficients used in the discriminant function are

5 obtained by maximising a margin criterion (Lizarazo 2008). The Gaussian Radial Basis

6 Function (RBF) kernel was applied (Scholkopf et al. 1997), and the two parameters C

7 and $\gamma$ were tuned using a grid search in this study. The $\gamma$ parameter defines how far the

8 influence of a single training sample reaches, with low values meaning 'far' and high

9 values meaning 'close'. The $\mathrm{C}$ parameter trades off misclassification of training samples

10 against simplicity of the classification boundaries. A low $\mathrm{C}$ makes the classification

11 boundaries smooth, whereas a high $\mathrm{C}$ aims at classifying all training examples correctly.

12 RF is an ensemble learning technique that builds multiple trees based on random

13 bootstrapped samples of the training data (Breiman 2001). Each tree is built using a

14 different subset from the original training data, containing approximately two thirds of

15 the cases, and the nodes are split using the best split variable among a subset of $\mathrm{m}$

16 randomly selected variables (Liaw and Wiener 2002). Through this strategy, RF is

17 robust to over-fitting and can handle thousands of input variables (dependent or

18 independent) without variable deletion (Breiman 2001). The output is determined by a

19 majority vote of the trees. Two user-defined parameters are the number of trees (k) and

20 the number of variables used to split the nodes (m); when the number of trees is

21 increased, the generalisation error always converges, and over-training is not a problem.

22 On the other hand, a reduction in the number $m$ of predictive variables results in each

23 individual tree of the model being weaker; therefore, picking a large number of trees is

24 recommended, as is using the square root of the number of variables for the value of $\mathrm{m}$

25 (Breiman 2001). 
These classifications algorithms were applied using R (R Core Team 2013),

2 'rpart' package (Therneau et al. 2013), 'randomForest' package (Liaw and Wiener 2002)

3 and 'kernlab' package (Karatzoglou et al. 2013). All fields were buffered inward by 10

$4 \mathrm{~m}$, accounting for field shape. The buffer was used to avoid selecting training pixels

5 from the edge of a field, which would create a mixed signal and affect the accuracy

6 assessment.

7 We used a stratified random-sampling approach to select the fields used for

8 training. Approximately $20 \%$ of the crop fields were selected at random as training

9 samples. The number of samples for each crop type was determined based on the

10 percentage of fields in the area. The remaining $80 \%$ of fields were used to perform the

11 accuracy assessment.

12 Classification was performed using the training data in 2009 to classify the test

13 data in 2009 (same-year classification). Furthermore, analysis of the cross-year training

14 and classification was performed using the training data in 2009 to classify the data in

152012 (cross-year classification). Therefore, the crop types of training plots have not

16 changed for the data in 2012. In this study, the selected classification algorithms were

17 classification and regression tree (CART), support-vector machine (SVM) and random

18 forests (RF).

19 The classification maps were evaluated in terms of their overall accuracy (OA),

20 producer's accuracy (PA) and user's accuracy (UA). Furthermore, the two simple

21 measures of quantity disagreement (QD) and allocation disagreement (AD), which are

22 much more useful to summarise a cross-tabulation matrix than the kappa index of

23 agreement, were used for evaluation (Pontius and Millones 2011). The significant

24 differences among the results were determined at the 95\% level of significance using

25 the Z-test, which was performed for a pairwise comparison of the proposed methods and 
1 accounted for the ratio between the difference values of two kappa coefficients and the

2 difference in their respective variances (Congalton and Green 2008).

\section{4. Results and discussion}

4 To apply SVM, the optimal values of the two parameters, $\mathrm{C}$ and $\gamma$, were examined.

5 Table 4 represents the relationships between the two parameters and overall accuracy of

6 the same-year classifications. The higher accuracy observed in the central range of $\mathrm{C}$

7 and $\gamma$ indicates that nearby same power combination but with opposite sign leads to

8 higher classification accuracy in Table 4 . Thus, the parameter pair $(C, \gamma)=\left(2^{-5}, 2^{6}\right)$ was

9 chosen as the optimal parameters in this study.

$<$ Table 4>

11 For application of RF, the number of trees was tuned, and Figure 3 represents

12 the relationships between the number of trees and the error rate for OOB. Because the

13 results indicate that a number of more than 50 is suitable, 50 was chosen as the number

14 of trees in this study.

$<$ Figure 3>

16 The corresponding confusion matrixes of classifications using TerraSAR-X data are

17 given in Table 5, and SVM was the best classification algorithm for the both

18 classifications. Although it is impossible to compare the results with earlier studies due

19 to the different study area and the crop types, the overall accuracies of the same year classification are close to the results using backscatter data of three ENVISAT/ASAR data and TerraSAR-X data for crop classification in the North China Plain (Jia et al. 22 2012).

Figure 5 represents the weather conditions in 2009 and 2012. The harvesting

24 periods of winter wheat were approximately the same, regardless of the difference in the climate conditions. Thus, the PAs and UAs in the cross-year classification were more 
1 than $88 \%$ for wheat. For other crops, in 2012, due to the higher air temperature in

2 August to September, the crop growth was advanced 2-5 days earlier than in the normal

3 year, whereas the crop growth was delayed 2-7 days in 2009 , according to the

4 announcements by Tokachi Subprefecture

5 (http://www.tokachi.pref.hokkaido.lg.jp/ss/nkc/). In particular, the difference in the

6 growing conditions was large for maize (8 days). To make matters worse, in September

7 the acquisition date in 2012 was 4 days later than that in 2010. The PAs and UAs in the

8 cross-year classification were very low. Nevertheless, the overall accuracy of the cross-

9 year classification using RF or SVM was close to that of Hartfield et al. (2013), which

10 indicated 71-83\% using Landsat Thematic Mapper (TM) image data.

11 We used the Z-test to compare the accuracy of the classification methods

12 because the same samples and the same assessment points were used for each

13 classification. The CART, SVM and RF classifications were compared to determine

14 whether they produced significantly different results, as shown in Table 6. Based on a

15 comparison of the overall accuracies, the SVM and RF algorithms were the most

16 accurate for same-year classification because the difference between SVM and RF was

17 not meaningful $(p<0.05)$, as shown in Table 4. However, in the case of cross-year

18 classification, these algorithms differed from each other, and the SVM algorithm was

19 the most accurate (Figure 4).

20

21
$<$ Table 5>

$<$ Table 6>

$<$ Figure 4>

\section{Conclusions}

To generate classification maps, in this study, three StripMap images from TerraSAR-X were used, and three algorithms, CART, SVM and RF, were applied. SVM was the best 
1 classification algorithm for both classifications in terms of OA, QD and AD, and the

2 difference of the cross-year classification result was meaningful $(p<0.05)$. Using the

3 training data from one year and applying those data to another year for classification

4 purposes resulted in an overall accuracy of $78.0 \%$.

These results allow for the automatic and consistent crop type classifications for

6 the six defined classes. The approach offers possibilities to generate crop classification

7 maps to estimate the amount of crops harvested or agricultural disaster compensation

8 with little human power, which has significant cost. Interpretation of the entropy-alpha

9 decomposition may improve the accuracy of the classification due to understanding of

10 the scattering mechanism. In future studies, the potential of the entropy-alpha

11 decomposition for crop type classification will be tested.

\section{Acknowledgements}

13 This work was supported by JSPS KAKENHI Grant Number $26 \cdot 5253$. The field data were provided by Tokachi Nosai (http://www.tokachi-nosai.or.jp/).

Finally, many thanks to Prof. Michael Collins and the three anonymous reviewers for their important insights, which improved this article.

\section{References}

Ager, T.P. and P.C. Bresnahan. 2009. Geometric precision in space radar imaging: Results from TerraSAR-X. In ASPRS 2009 annual conference, 9-13. Baltimore, Maryland, USA.

Bargiel, D. and S. Herrmann. 2011. Multi-temporal land-cover classification of agricultural areas in two European regions with high resolution spotlight TerraSAR-X data. Remote Sensing 3, no 5: 859-877.

Beriaux, E., C. Lucau-Danila, E. Auquiere and P. Defourny. 2013. Multiyear independent validation of the water cloud model for retrieving maize leaf area index from SAR time series. International Journal of Remote Sensing 34, no 12: 4156-4181.

Blaes, X. and P. Defourny. 2003. Retrieving crop parameters based on tandem ERS 1/2 interferometric coherence images. Remote Sensing of Environment 88, no 4: 374-385. 
Blaes, X., P. Defourny, U. Wegmuller, A. Della Vecchia, L. Guerriero and P. Ferrazzoli. 2006. C-band polarimetric indexes for maize monitoring based on a validated radiative transfer model. IEEE Transactions on Geoscience and Remote Sensing 44, no 4: 791-800.

Bovolo, F., L. Bruzzone and L. Carlin. 2010. A novel technique for subpixel image classification based on support vector machine. IEEE Transactions on Image Processing 19, no 11: 2983-2999.

Breiman, L. 2001. Random forests. Machine Learning 45, no 1: 5-32.

Brisco, B., A. Schmitt, K. Murnaghan, S. Kaya and A. Roth. 2013. SAR polarimetric change detection for flooded vegetation. International Journal of Digital Earth 6 , no 2: 103-114.

Choudhury, I. and M. Chakraborty. 2006. SAR signature investigation of rice crop using radarsat data. International Journal of Remote Sensing 27, no 3: 519-534.

Congalton, R.G. and K. Green. 2008. Assessing the accuracy of remotely sensed data: Principles and practices. Boca Raton, Florida, United States: CRC Press.

Cortes, C. and V. Vapnik. 1995. Support-vector networks. Machine Learning 20, no 3: 273-297.

Costa, M. P. F. 2004. Use of SAR satellites for mapping zonation of vegetation communities in the Amazon floodplain. International Journal of Remote Sensing, 25, no 10:1817-1835.

Duro, D., S. Franklin and M. Dube. 2012. Multi-scale object-based image analysis and feature selection of multi-sensor earth observation imagery using random forests. International Journal of Remote Sensing 33, no 14: 4502-4526.

Fontanelli, G., S. Paloscia, M. Zribi and A. Chahbi. 2013. Sensitivity analysis of Xband SAR to wheat and barley leaf area index in the merguellil basin. Remote Sensing Letters 4, no 11: 1107-1116.

Foody, G. and A. Mathur. 2004. A relative evaluation of multiclass image classification by support vector machines. IEEE Transactions on Geoscience and Remote Sensing 42, no 6: 1335-1343.

Gislason, P., J. Benediktsson and J. Sveinsson. 2006. Random forests for land cover classification. Pattern Recognition Letters 27, no 4: 294-300.

Hartfield, K., S. Marsh, C. Kirk and Y. Carriere. 2013. Contemporary and historical classification of crop types in Arizona. International Journal of Remote Sensing 34, no 17: 6024-6036.

Jia, K., Q. Li, Y. Tian, B. Wu, F. Zhang and J. Meng. 2012. Crop classification using multi-configuration SAR data in the North China Plain International Journal of Remote Sensing 33, no 1: 170-183.

Karatzoglou, A., A. Smola and K. Hornik. Package 'kernlab'. http://cran.rproject.org/web/packages/kernlab/kernlab.pdf.

Kavzoglu, T. and I. Colkesen. 2013. An assessment of the effectiveness of a rotation forest ensemble for land-use and land-cover mapping. International Journal of Remote Sensing 34, no 12: 4224-4241.

Kuenzer, C. and K. Knauer. 2013. Remote sensing of rice crop areas. International Journal of Remote Sensing 34, no 6: 2101-2139.

Liaw, A. and M. Wiener. 2002. Classification and regression by random forest. $R$ News 2, no 3: 18-22.

Lievens, H. and N. Verhoest. 2011. On the retrieval of soil moisture in wheat fields from L-band SAR based on water cloud modeling, the IEM, and effective roughness parameters. IEEE Geoscience and Remote Sensing Letters 8, no 4: 740-744. 
Lizarazo, I. 2008. Svm-based segmentation and classification of remotely sensed data. International Journal of Remote Sensing 29, no 24: 7277-7283.

Mattia, F., T. Le Toan, G. Picard, F. Posa, A. D'alessio, C. Notarnicola, A. Gatti, M. Rinaldi, G. Satalino and G. Pasquariello. 2003. Multitemporal C-band radar measurements on wheat fields. IEEE Transactions on Geoscience and Remote Sensing 41, no 7: 1551-1560.

Mishra, N.B. and K.A. Crews. 2014. Mapping vegetation morphology types in a dry savanna ecosystem: Integrating hierarchical object-based image analysis with random forest. International Journal of Remote Sensing 35, no 3: 1175-1198.

Otsu, N. 1979. A threshold selection method from gray-level histograms. IEEE Transactions on Systems, Man, and Cybernetics 9 no 1, 62-66.

Pal, M. 2005. Random forest classifier for remote sensing classification. International Journal of Remote Sensing 26, no 1: 217-222.

Pal, M. 2008. Ensemble of support vector machines for land cover classification. International Journal of Remote Sensing 29, no 10: 3043-3049.

Pontius, R. and M. Millones. 2011. Death to kappa: Birth of quantity disagreement and allocation disagreement for accuracy assessment. International Journal of Remote Sensing 32, no 15: 4407-4429.

R Core Team. 2013. A Language and Environment for Statistical Computing. Vienna: R Foundation for Statistical Computing. Accessed October 11. http://www.Rproject.org/

Rodriguez-Galiano, V., M. Chica-Olmo, F. Abarca-Hernandez, P. Atkinson and C. Jeganathan. 2012. Random forest classification of mediterranean land cover using multi-seasonal imagery and multi-seasonal texture. Remote Sensing of Environment 121: 93-107.

Roth, A., M. Huber and D. Kosmann. 2004. Geocording of TerraSAR-X data. In 20th ISPRS Congress, 840-844. Istanbul.

Sarker, L. and J. Nichol. 2011. Improved forest biomass estimates using alos avnir-2 texture indices. Remote Sensing of Environment 115, no 4: 968-977.

Scholkopf, B., K. Sung, C. Burges, F. Girosi, P. Niyogi, T. Poggio and V. Vapnik. 1997. Comparing support vector machines with gaussian kernels to radial basis function classifiers. IEEE Transactions on Signal Processing 45, no 11: 27582765.

Sonobe, R., H. Tani, X. Wang, N. Kobayashi and H. Shimamura. 2014a. Random forest classification of crop type using multi-temporal TerraSAR-X dual-polarimetric data. Remote Sensing Letters 5, no 2: 157-1564.

Sonobe, R., H. Tani, X. Wang, N. Kobayashi, A. Kimura and H. Shimamura. 2014b. Application of multi-temporal TerraSAR-X data to map winter wheat planted areas in Hokkaido, Japan. Japan Agricultural Research Quarterly 48, no 4: 465470.

Sonobe, R., H. Tani, X. Wang, N. Kobayashi and H. Shimamura. 2014c. Winter wheat growth monitoring using multi-temporal TerraSAR-X dual-polarimetric data. Japan Agricultural Research Quarterly 48, no 4: 471-476.

Therneau, T., B. Atkinson and B. Riple. Package 'rpart'. http://cran.rproject.org/web/packages/rpart/rpart.pdf.

Ulaby, F.T., M.K. Moore and A.K. Fung. 1986. Microwave remote sensing active and passive. Norwood: Artech House.

Vyas, S., M. Steven, K. Jaggard and H. Xu. 2003. Comparison of sugar beet crop cover estimates from radar and optical data. International Journal of Remote Sensing 24, no 5: 1071-1082. 
1 Table 1. Cultivation calendar for the crops in this study area.

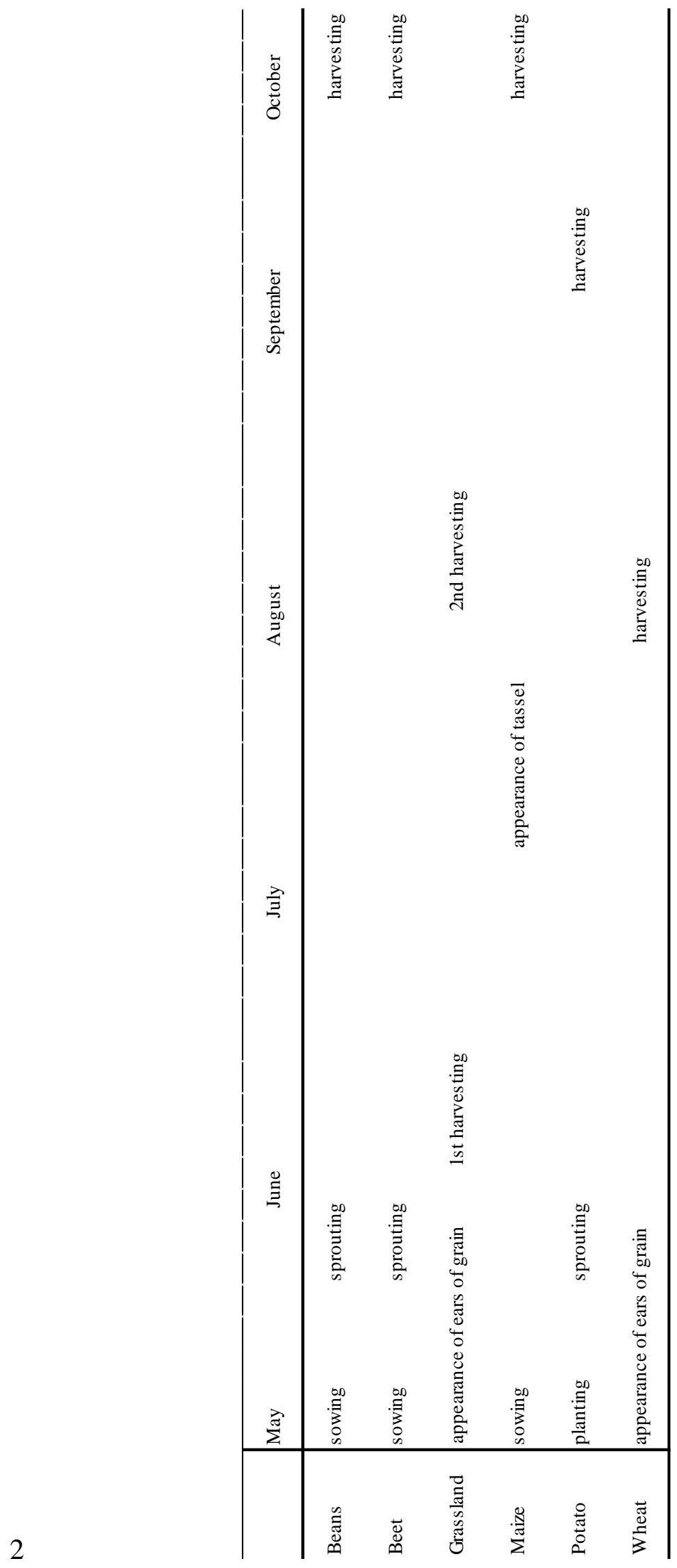


1 Table 2. Characteristics of the satellite images used.

\begin{tabular}{ccccccc}
\hline Satellite & Mode & Polarisation & Acquisition date & Orbit & $\begin{array}{c}\text { Pixel spacing } \\
(\mathrm{m})\end{array}$ & $\begin{array}{c}\text { Incidence } \\
\text { angle }\left({ }^{\circ}\right)\end{array}$ \\
\hline TerraSAR-X & StripMap & HH, VV & 7 July, 2009 & Ascending & 2.75 & 42.3 \\
TerraSAR-X & StripMap & HH, VV & 9 August, 2009 & Ascending & 2.75 & 42.3 \\
TerraSAR-X & StripMap & HH, VV & 31 August, 2009 & Ascending & 2.75 & 42.3 \\
TerraSAR-X & StripMap & HH, VV & 11 September, 2009 & Ascending & 2.75 & 42.3 \\
TanDEM-X & StripMap & HH, VV & 11 July, 2012 & Ascending & 2.75 & 42.3 \\
TanDEM-X & StripMap & HH, VV & 2 August, 2012 & Ascending & 2.75 & 42.3 \\
TanDEM-X & StripMap & HH, VV & 24 August, 2012 & Ascending & 2.75 & 42.3 \\
TanDEM-X & StripMap & HH, VV & 15 September, 2012 & Ascending & 2.75 & 42.3 \\
\hline
\end{tabular}

2 
1 Table 3. Crop type and number of fields.

No. of fields

\begin{tabular}{cccc} 
Crop type & \multicolumn{2}{c}{ Data acquired in 2009 } & Data acquired in \\
& Training data & Test data & 2012 \\
\hline Beans & 211 & 842 & 960 \\
Beet & 142 & 567 & 625 \\
Grassland & 124 & 499 & 644 \\
Maize & 50 & 204 & 583 \\
Potato & 167 & 664 & 749 \\
Wheat & 297 & 1188 & 1513 \\
\hline
\end{tabular}


1 Table 4. Relationships between the overall accuracy and the parameters of SVM.

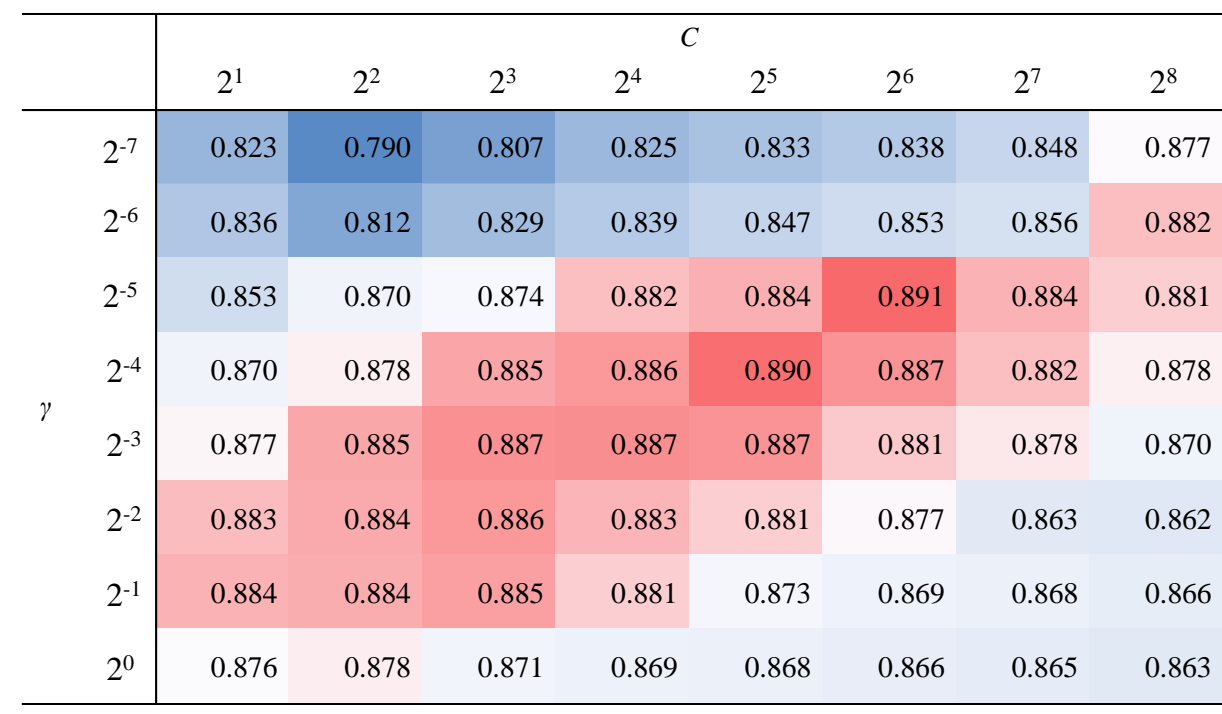


1 Table 5. Accuracy results.

\begin{tabular}{|c|c|c|c|c|c|c|}
\hline \multirow[b]{2}{*}{ Class } & \multicolumn{2}{|c|}{$\begin{array}{c}\text { classification and } \\
\text { regression tree (CART) }\end{array}$} & \multicolumn{2}{|c|}{ random forest $(\mathrm{RF})$} & \multicolumn{2}{|c|}{$\begin{array}{l}\text { support vector machine } \\
\text { (SVM) }\end{array}$} \\
\hline & $\begin{array}{c}\text { Test data } \\
\text { acquired } \\
\text { in } 2009 \\
\end{array}$ & $\begin{array}{c}\text { Data } \\
\text { acquired } \\
\text { in } 2012 \\
\end{array}$ & $\begin{array}{l}\text { Test data } \\
\text { acquired } \\
\text { in } 2009 \\
\end{array}$ & $\begin{array}{c}\text { Data } \\
\text { acquired } \\
\text { in } 2012\end{array}$ & $\begin{array}{c}\text { Test data } \\
\text { acquired } \\
\text { in } 2009\end{array}$ & $\begin{array}{c}\text { Data } \\
\text { acquired } \\
\text { in } 2012 \\
\end{array}$ \\
\hline \multicolumn{7}{|l|}{$\mathrm{PA}$} \\
\hline Beans & 0.678 & 0.460 & 0.802 & 0.542 & 0.859 & 0.630 \\
\hline Beet & 0.785 & 0.562 & 0.937 & 0.734 & 0.951 & 0.946 \\
\hline Grassland & 0.810 & 0.814 & 0.896 & 0.856 & 0.834 & 0.873 \\
\hline Maize & 0.426 & 0.058 & 0.466 & 0.122 & 0.608 & 0.110 \\
\hline Potato & 0.858 & 0.818 & 0.893 & 0.874 & 0.886 & 0.907 \\
\hline Wheat & 0.962 & 0.887 & 0.960 & 0.962 & 0.960 & 0.963 \\
\hline \multicolumn{7}{|l|}{ UA } \\
\hline Beans & 0.801 & 0.522 & 0.818 & 0.571 & 0.853 & 0.564 \\
\hline Beet & 0.878 & 0.680 & 0.863 & 0.873 & 0.822 & 0.847 \\
\hline Grassland & 0.884 & 0.681 & 0.871 & 0.804 & 0.929 & 0.813 \\
\hline Maize & 0.554 & 0.810 & 0.792 & 0.826 & 0.832 & 0.821 \\
\hline Potato & 0.674 & 0.420 & 0.879 & 0.490 & 0.899 & 0.668 \\
\hline Wheat & 0.890 & 0.931 & 0.938 & 0.952 & 0.944 & 0.960 \\
\hline OA & 0.812 & 0.652 & 0.878 & 0.732 & 0.891 & 0.780 \\
\hline QD & 7.013 & 16.456 & 2.548 & 12.712 & 2.926 & 9.953 \\
\hline $\mathrm{AD}$ & 11.756 & 18.388 & 9.637 & 14.131 & 7.997 & 12.042 \\
\hline
\end{tabular}

2 Note: PA, producer's accuracy; UA, user's accuracy; OA, overall accuracy; QD,

3 quantity disagreement; $\mathrm{AD}$, allocation disagreement.

4 
1 Table 6. $Z$-test results for the classification.

\begin{tabular}{|c|c|c|c|}
\hline \multicolumn{2}{|c|}{ classification } & SVM & $\mathrm{RF}$ \\
\hline \multirow{2}{*}{ same-year } & CART & 10.22 & 8.42 \\
\hline & SVM & & 1.8 \\
\hline \multirow{2}{*}{ cross-year } & CART & 15.49 & 9.61 \\
\hline & SVM & & 5.83 \\
\hline
\end{tabular}

2 
1 Figures

2 Figure 1. The study area (background map shows the TerraSAR-X data acquired on 2 May, 3 2009).

4

5 Figure 2. Overview of the data processing.

6

7 Figure 3. Relationships between the number of trees and the error rate for OOB samples.

8

9 Figure 4. Crop type classification map in 2012 using SVM.

10

11 Figure 5. Weather conditions in 2009 and 2012. 


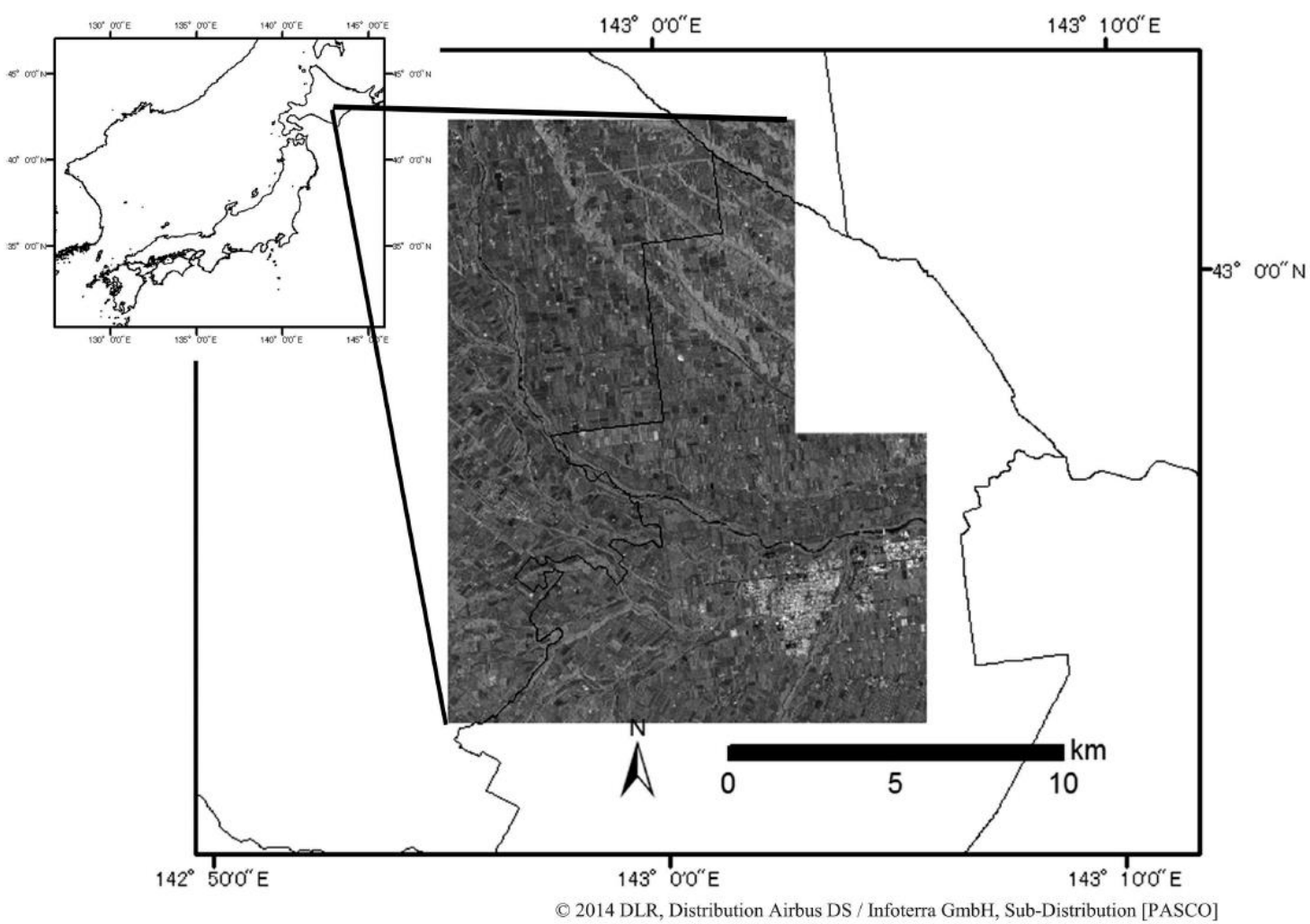

1

2 Figure 1. The study area (background map shows the TerraSAR-X data acquired on 2 May, 3 2009). 


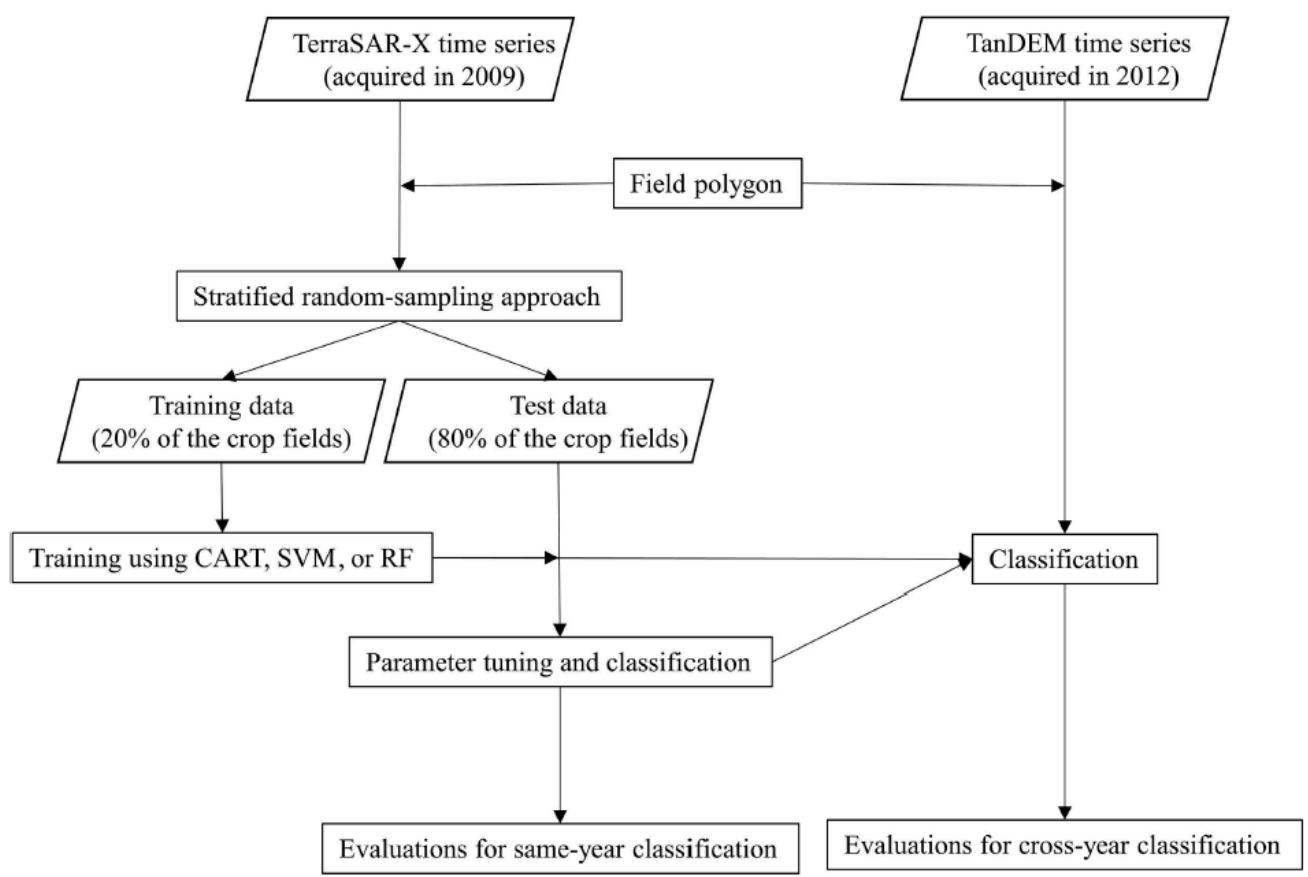

2 Figure 2. Overview of the data processing. 


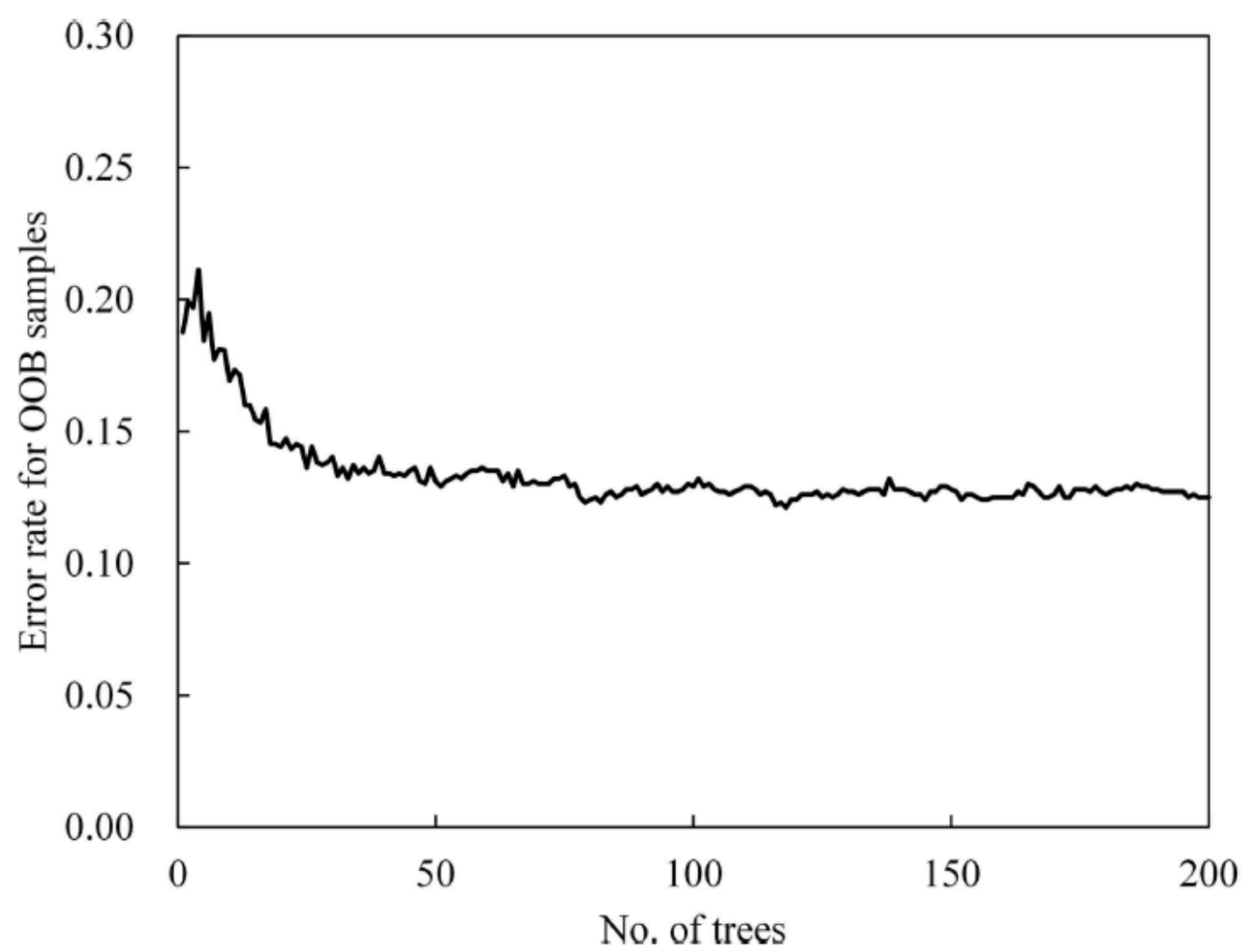

1

2 Figure 3. Relationships between the number of trees and the error rate for OOB samples. 3 


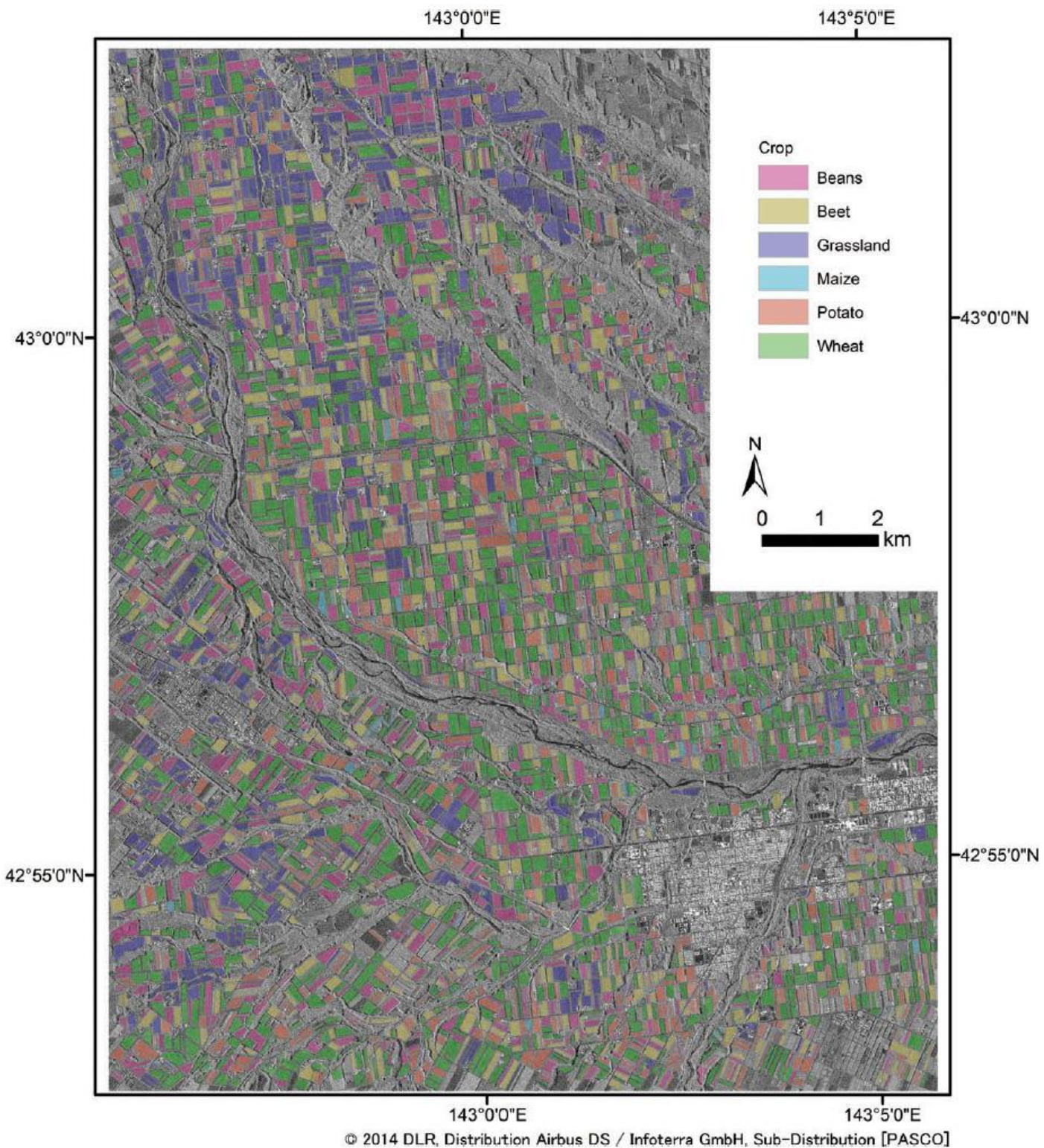

(1) 2014 DLR, Distribution Airbus DS / Infoterra GmbH, Sub-Distribution [PASCO]

2 Figure 4. Crop type classification map in 2012 using SVM. 


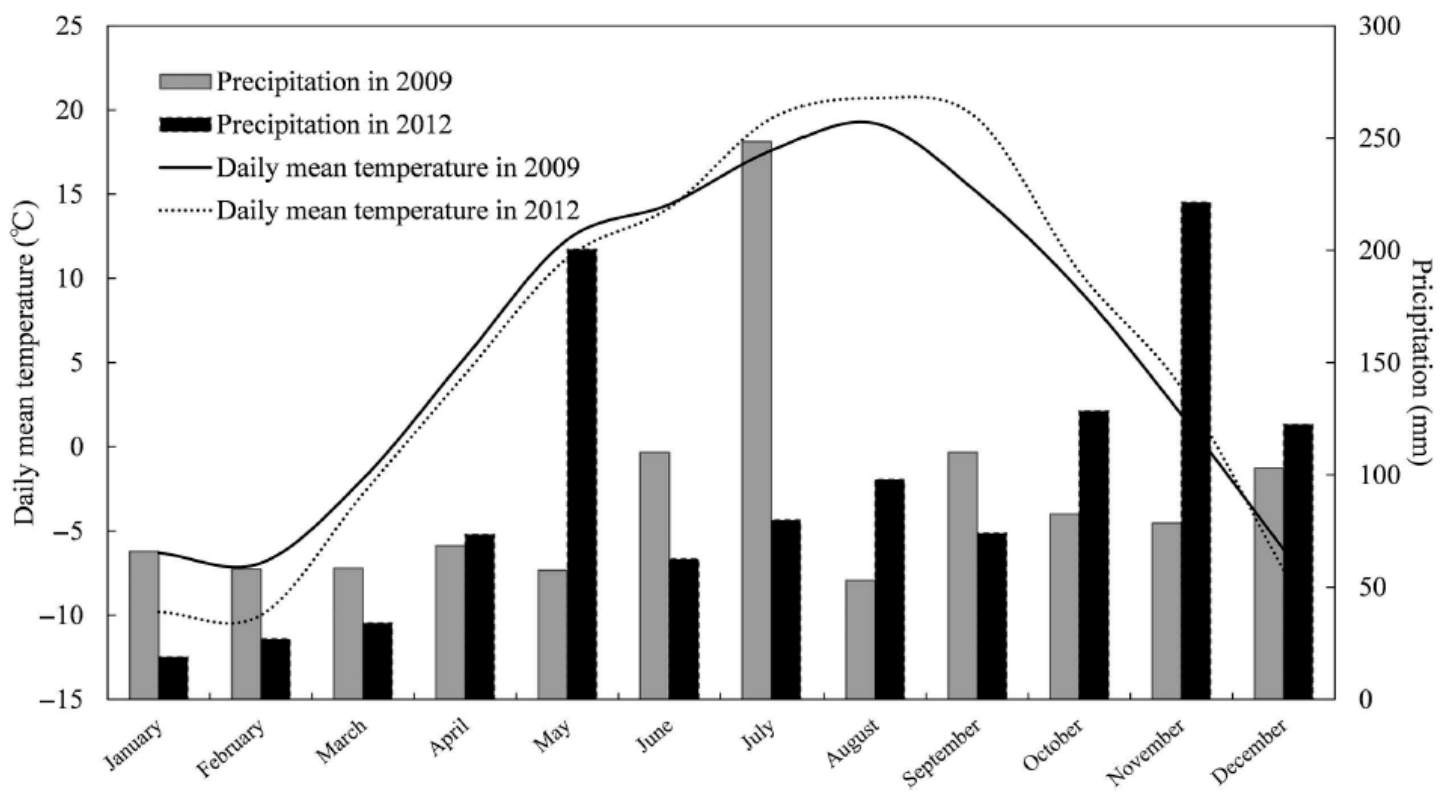

1

2 Figure 5. Weather conditions in 2009 and 2012. 